\title{
Orçamento executivo como ferramenta do processo de planejamento e controle de custos de obras públicas
}

\author{
Adriana de Paula Lacerda Santos ${ }^{1}$, Luciana Emília Machado Garcia ${ }^{1}$
}

\author{
${ }^{1}$ Universidade Federal do Paraná. \\ Correspondência: E-mail: adrianapls1@gmail.com.br \\ Centro Politécnico, $s / n$ \\ Curitiba - PR - Brasil \\ CEP $81531-990$
}

Resumo

O objetivo deste artigo e apresentar uma lógica de execução do orçamento executivo para ser utilizado em obras públicas e que possa auxiliar no seu processo de planejamento e controle de custos de obras públicas. Para tanto, realizado um estudo de caso em uma Instituição Federal de Ensino Superior (IFES). Após a coleta e análise dos dados foi verificado que o método mais usual de planejar as obras de engenharia no setor público baseia-se na elaboração de desenhos de projetos e no orçamento convencional. Tal metodologia tem apresentado ser ineficiente frente ao grande número de aditivos contratuais e das obras fora do prazo de execução e/ou não concluídas na IFES. Com a implantação do orçamento executivo, ajustado à realidade da IFES, foi possível identificar que existem possibilidades significativas de melhora no processo de gerenciamento das obras púbicas.

Palavras-chave: construção civil, planejamento, gestão de custos, gestão pública.

Abstract The aim of this study consists in proposing an executive budget for use in public works which can help in its planning process and the cost control of public construction works. To do so, as a research strategy, it was used a case study, in a Federal Institution of Higher Education (IFES). After collecting and analyzing data was verified that the most usual method of planning engineering works in the public sector is based on preparation of project drawings (architectural, structural, hydraulic and electric) and the conventional budget. This methodology has shown to be inefficient with the large number of contractual additives and works out of the execution time (late) and/or noncompletion in the IFES. With the implementation of the executive budget, adjusted to the IFES reality, it was possible to identify that 
there are significant improvement possibilities in the management process of public construction works.

Keywords: civil construction, planning, cost management, public management.

Resumen El objetivo del artículo es presentar una lógica de ejecución del estudio ejecutivo ser usado en obras públicas y que pueda auxiliar en el proceso de planeamiento e control de costos de las obras públicas. Así, fue realizado un estudio de caso en una Institución Federal de Enseño Superior (IFES). Después de la coleta y análisis de los datos, fue verificado que el método más usual de planear las obras de ingeniería en el sector público es basado en la elaboración de diseños de proyectos y el estudio convencional. La metodología tiene presentado ineficiencias deudo al gran número de aditivos contractuales y de las obras fuera del plazo de ejecución y/o non concluidas en la IFES. Con la implantación del estudio ejecutivo, ajustado a la realidad de la IFES, fue posible identificar posibilidades significativas de mejora en el proceso de gestión de las obras púbicas.

Palabras-clave: construcción civil, planeamiento, gestión de costos, gestión pública. 


\section{Introdução}

O gerenciamento de obras públicas consiste na elaboração do projeto de engenharia, orçamento, licitação, contratação, execução e recebimento da obra.

Para se avaliar a viabilidade de execução de um empreendimento, é necessário que se estime previamente o seu custo. Tal estimativa é feita através da elaboração do orçamento. No modelo de administração pública tradicional a licitação é o precedente necessário para a contratação de obras públicas. As obras e serviços somente poderão ser licitados se houver projeto básico e orçamento detalhado em planilhas que expressem a composição de todos os seus custos unitários, conforme artigo 70 da lei 8.666/93 (Andrade e Souza 2002, Santos et al. 2002).

Para a realização de obras, serviços, inclusive de publicidade, compras, alienações e locações para a Administração Pública, faz-se necessário atender a lei federal 8.666/93, conhecida como Lei de Licitações e Contratos. Esses serviços e obras são denominados como objeto da licitação.

Conforme o artigo $2^{\circ}$, da referida Lei, as obras e serviços devem ser precedidos necessariamente de licitação. Segundo o artigo 3 da lei 8.666/93, a licitação é necessária para garantir que haja isonomia entre as empresas concorrentes e também para ajudar a selecionar a proposta mais vantajosa para a administração pública. Geralmente, a administração pública seleciona a proposta que apresenta o menor preço para a realização do objeto da licitação.

Escolher uma empresa apenas pelo menor preço não é o melhor critério para cumprir com os objetivos da licitação, nivelando por baixo a qualidade da construção ou do serviço causando a gradativa deterioração da estrutura produtiva do setor da construção como um todo (Tisaka 2005).

Atualmente, os profissionais que trabalham na área de engenharia de custos têm assumido papel de destaque nas organizações de governo, em que esses técnicos atuam como contratantes e gestores, desde a elaboração das licitações até o recebimento final das obras. A capacidade de prever as estimativas de custo de uma construção pode resultar em propostas mais precisas (Cardoso 2009, Ashuri e Lu 2010).

No mercado da construção civil, há vários exemplos de licitações ganhas e não iniciadas, ou mal-acabadas ou mesmo não concluídas, trazendo paralisações, atrasos e grandes problemas para a administração e sérios prejuízos para a sociedade (Tisaka 2006).

Quando uma obra é malfeita, além de ter que ser refeita, muitas vezes com má qualidade, custa mais caro do que aquela que foi bem-feita por um preço justo, ou seja, um preço coerente com a realidade do mercado no momento da licitação (Tisaka 2006). Mesmo sendo restritas pelas limitações legais, as alterações que 
ocorrem nos contratos, frequentemente ensejam a perda da vantagem que fora obtida na licitação, causando prejuízos aos cofres públicos (Nunes e Freire 2002).

Com o planejamento de custo é possível criar um sistema que garanta o cumprimento das metas pré-estabelecidas para a execução dos empreendimentos, além de propiciar alternativas técnicas capazes de reduzir custos e a promoção da evolução tecnológica (Goldman 1999).

Dentro dessa linha de gestão de custos integrada às atividades de planejamento surge o orçamento executivo que pode gerar um aumento da eficácia dos orçamentos (Santos 2002).

O orçamento é a peça-chave no processo licitatório, se não a mais importante. É sem dúvida, o documento adequado para, em representando um determinado projeto, receber o parecer de aprovação pela auditoria/controladoria. É o documento por meio do qual o auditor acessa as mais variadas informações dos projetos de arquitetura e de engenharia, podendo ainda efetuar diversas confrontações com os documentos e relatórios de prestação de contas (Cardoso 2009).

Analisar os orçamentos dos empreendimentos sob o aspecto do planejamento, dimensionamento dos custos e previsão de receitas para a execução de obras, no prazo estipulado é de vital importância para a correta gestão da verba pública (Domingues 2003).

De fato, o orçamento é um documento valioso em qualquer estudo preliminar ou de viabilidade. Uma obra iniciada e sem a definição do seu custo, ou sem previsão adequada dos recursos necessários, pode resultar em uma obra inacabada (Cardoso 2009).

Neste contexto, este artigo apresenta o orçamento executivo como uma ferramenta que pode ser utilizado para facilitar o planejamento e controle de custos de obras públicas.

\section{Gerenciamento de custos}

O custo é definido como valor relativo a um bem ou serviço que é utilizado na produção de outro bem ou serviço. Difere da despesa, a qual é definida como um bem ou serviço consumido direta ou indiretamente para a obtenção de receitas, sendo normalmente relacionada à administração, às vendas e aos financiamentos (Araújo 2003).

O gerenciamento de custos do projeto faz estimativas dos custos de cada um dos pacotes de trabalho, dos subsistemas, e de todo o projeto, e estabelece o orçamento para o projeto inteiro. Envolve a comparação dos custos planejados com os custos reais incorridos em vários pontos do projeto e a estimativa dos 
custos restantes, como também a atualização das estimativas de custos finais. É a soma de todas as ações necessárias para o planejamento, monitoração e controle dos custos durante o ciclo de vida do projeto, incluindo-se a avaliação do projeto e as estimativas de custos nas primeiras fases do projeto (IPMA 2006).

O controle de custos consiste no monitoramento da execução de ajustes no cronograma a fim de adequá-lo ao plano e fazer os replanejamentos se necessário. Trata-se de uma análise gerencial que pode e deve ser exercida antes, durante ou após a produção de bens e serviços (Oliveira e Perez Jr. 2000, Valeriano 2007).

Os principais objetivos de controlar os custos são (Oliveira e Perez Jr. 2000):

a) Fornecer informações gerenciais para a administração a fim de subsidiar as tomadas de decisões;

b) Servir como instrumento de controle sobre as atividades operacionais e produtivas de uma entidade;

c) Demonstrar as distorções de valores, níveis de produtividade e eficiência da produção de bens e serviços, em relação às metas da empresa e padrões estabelecidos;

d) Contribuir para a apuração de índices econômicos, financeiros e de lucratividade;

e) Avaliar a eficácia e eficiência na utilização dos fatores produtivos;

f) Identificar falhas nos processos produtivos e atividades que não agregam valores aos produtos;

g) Fornecer subsídios para a política de terceirização de determinadas atividades;

h) Identificar a capacidade ociosa da produção.

\section{Gerenciamento de custos na construção civil}

A indústria da construção civil caracteriza-se por um sistema de produção distinto da maioria das indústrias. Tradicionalmente, a forma de apuração de custos é através do custo padrão, que utiliza índices extraídos de tabelas (Castro et al. 1997). 
Os custos da construção civil são classificados em: custos diretos (mão-de-obra, materiais, equipamentos) e custos indiretos (administração da obra e administração central (Castro et al. 1997).

Para alocar esses custos indiretos à obra utiliza-se o BDI (Benefício e Despesas Indiretas ou Bonificação e Despesas Indiretas) que é uma taxa de mark-up, obtida através de equações matemáticas para a formação do preço de venda de serviços de engenharia, sendo aplicado no ramo da construção civil brasileira desde meados da década de 1970. Este índice também engloba o lucro desejado (Castro et al. 1997, Freires e Pamplona 2005).

Mark-up é uma prática muito comum e simples de determinação de preço, pois consiste em adicionar ao custo unitário as porcentagens relativas aos itens a serem incluídos no preço tais como: impostos, despesas variáveis, despesas fixas, custos fixos e lucro. A utilização descuidada do mark-up pode levar tanto a situações de perda de lucratividade quanto a situações de perda de negócios lucrativos. No ramo da construção civil, a simples utilização de um fator paramétrico como o BDI não é capaz de cobrir com segurança todos os aspectos e peculiaridades do setor (Mattos e Cruz 2007, Souza e Clemente 2007).

\section{Orçamento}

Nos dias atuais, tendo em vista um mercado cada vez mais competitivo e um consumidor bastante exigente, todo e qualquer empreendimento requer um estudo de viabilidade econômica, um orçamento detalhado e um rigoroso acompanhamento físico-financeiro da obra. Para se avaliar a viabilidade de um empreendimento faz-se necessário estimar seu custo. Esta estimativa é realizada através da elaboração do orçamento (Andrade e Souza 2002, Knolseisen 2003).

Pode-se conceituar orçamento como um instrumento de planejamento e de controle vinculado aos planos de produção e investimento com a finalidade de otimizar o rendimento dos recursos físicos e monetários à disposição da empresa. É definido como a determinação dos gastos necessários para a realização de um projeto através do levantamento da quantidade de serviços e seus respectivos preços unitários e o preço global do investimento. É a soma do custo direto, do custo indireto e do resultado estimado do contrato (lucro previsto) (Zdanowicz 1984, Limmer 1997, Coêlho 2006, Dias 2006).

O orçamento da obra é uma das primeiras informações que o empreendedor deseja conhecer ao estudar determinado projeto. Seja um empreendimento com fins lucrativos ou não, sabe-se que a construção implica gastos consideráveis e por isso devem ser determinados, já que, em função de seu valor, o empreendido estudado será considerado viável ou não (Goldman 2004).

De qualquer forma o orçamento deve ser executado antes do início da obra, possibilitando o estudo ou planejamento prévios, e também é útil para o controle 
da obra. É com base nele que advém o sucesso de qualquer empreendimento de construção. Somente após a conclusão do orçamento pode-se determinar a viabilidade técnico-econômica do empreendimento; o cronograma físicofinanceiro da obra; o cronograma detalhado do empreendimento e os relatórios para acompanhamento físico-financeiro (Coêlho 2006, González 2008).

Os orçamentos podem ser classificados como (Andrade 1996, Araújo 2003):

a) Convencional: é feito a partir de composições de custo, dividindo os serviços em partes e orçando por unidade de serviço;

b) Executivo: este tipo de orçamento preocupa-se com todos os detalhes de como a obra será executada, modelando os custos de acordo com a forma que eles ocorrem na obra ao longo do tempo;

c) Paramétrico: é um orçamento aproximado, utilizado em estudos de viabilidade ou consulta rápidas de clientes. Está baseado na determinação de constantes de consumo dos insumos por unidade de serviço;

d) Método pelas características geométricas: baseia-se na análise de custos por elementos de construção de edifícios do mesmo tipo e com alguma semelhança relativa do elemento analisado no edifício de estudo;

e) Processo de correlação: o custo é correlacionado com uma ou mais variáveis de mensuração, podendo ser uma correlação simples produtos semelhantes - ou uma correlação múltipla - o projeto é decomposto em partes ou itens;

f) Processo de quantificação: o custo é estimado através do levantamento das quantidades dos insumos para a execução da obra.

\section{Orçamento executivo}

Ao contrário do orçamento convencional que enxerga a obra como pronta, o orçamento executivo preocupa-se com todos os detalhes de como a obra vai ser construída. O orçamento executivo responde à necessidade de modelar os custos de acordo com a forma como eles incorrem no canteiro, ao longo do tempo (Galvão 1990 apud Domingues 2003).

O orçamento executivo consiste essencialmente em adequar as informações fornecidas pelo orçamento aos dados obtidos em obra segundo um conceito de operação, isto é, a tarefa deve ser executada pela mesma mão-de-obra, de forma 
contínua e com limites bem definidos. O orçamento executivo está intimamente ligado ao momento em que as atividades são executadas na obra (Limmer 1997).

O orçamento executivo tem como parâmetro orçado a atividade. Neste contexto, o planejamento da obra é realizado por meio de pacotes de trabalho seguindo a estratégia de execução do empreendimento (Librelotto et al. 1998).

A maior distinção entre o orçamento convencional e o executivo está no fator tempo (Figura 1). Enquanto que na abordagem convencional a orçamentação é feita com base na obra pronta, desconsiderando o processo envolvido na fase de execução, na abordagem do orçamento executivo parte-se de uma programação prévia, analisando detalhadamente todo o processo construtivo para se chegar a uma estimativa de custos detalhada. No orçamento executivo apenas os custos dos materiais são proporcionais as quantidades produzidas, enquanto que os custos de mão-de-obra e equipamentos são proporcionais ao tempo (Santos et al. 2002).

Figura 1. Diferenças entre o orçamento convencional e o orçamento executivo. ORÇAMENTO CONVENCIONAL

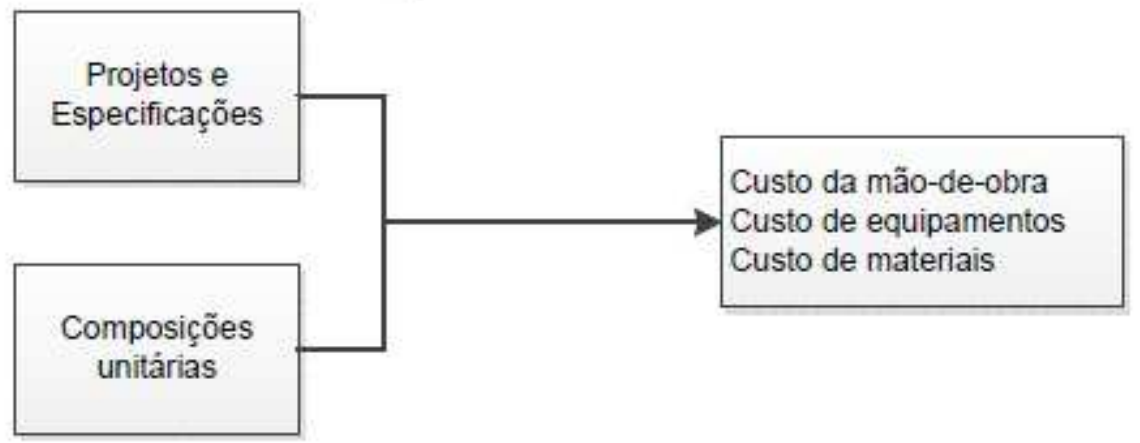

ORÇAMENTO OPERACIONAL

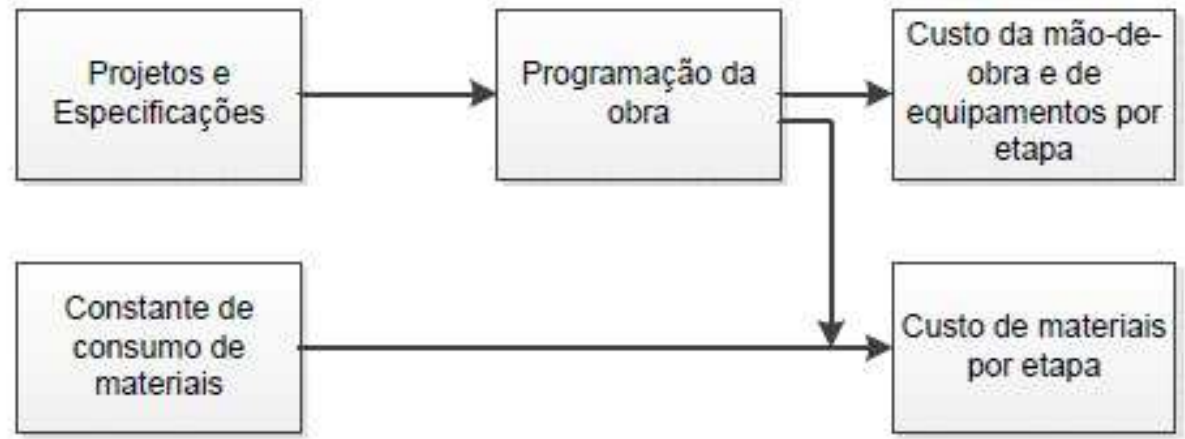

Fonte: Santos et al. (2002). 
A adoção de uma estrutura de orçamento em função do plano de ataque da obra, além de tornar os custos referentes à execução das atividades mais condizentes com a realidade pretendida, reduz os prazos de produção, explorando ao máximo a possibilidade de superposição de atividades, exigindo um planejamento executivo mais preciso e ao mesmo tempo, flexível. Assim sendo, é alcançado um aumento do poder de tomada de decisão em relação ao orçamento convencional (Bazanelli et al. 2003).

As vantagens da utilização do orçamento executivo são várias e essencialmente ligadas à transparência em que a obra é exposta, aumentando assim, o poder de decisão, uma vez considerados custo e tempo. Os parâmetros orçados estão intimamente relacionados com o momento de execução, propiciando o balanceamento das equipes de trabalho, considerando, inclusive, os tempos improdutivos de certas operações, e, além disso, é otimizado o setor de suprimentos, pois se torna transparente a cadência dos materiais necessários. Estas atitudes viabilizam o orçamento como uma fonte de racionalização do gerenciamento de obras (Cabral 1988 apud Bazanelli 2003).

Como desvantagem, o orçamento executivo apresenta um tempo para sua elaboração maior que o orçamento convencional, o orçamentista deve ser um profissional com grande conhecimento do processo produtivo e na programação da obra (Cabral 1988 apud Bazanelli 2003).

\section{Metodologia de pesquisa}

A pesquisa relatada neste artigo teve como objetivo contribuir para a busca da resposta para o seguinte problema pesquisa: "Como a utilização do orçamento executivo pode colaborar para o planejamento e controle de custos de obras públicas?".

Para tanto, como principal estratégia de pesquisa para o desenvolvimento do trabalho adotou-se o estudo de caso, pois de acordo com Gil (2007). Para a elaboração da pesquisa após a definição do problema de pesquisa, dos objetivos e pressupostos, foi realizada uma revisão bibliográfica abordando os conceitos de gerenciamento de projetos, planejamento e controle de obras, obras públicas e gerenciamento de custos.

A instituição escolhida foi uma Instituição Federal de Ensino Superior (IFES), na cidade de Curitiba (PR). A escolha desta IFES deve-se ao fato do pesquisar fazer parte integrante do quadro de servidores da Instituição, tendo assim, livre acesso a toda a documentação necessária para sua pesquisa.

Foram selecionados três casos (obras) para estudar. Os instrumentos utilizados para coletar informações foram a observação direta e participante, análise de documentos e entrevista semiestruturada. 
Com a coleta de dados e em conjunto com a revisão bibliográfica foi possível fazer uma análise dos dados individualmente e em conjunto dos três estudos de caso escolhidos para então obter subsídios para a elaboração de uma lógica de execução do orçamento executivo aplicado às obras públicas com a finalidade de auxiliar no planejamento e controle das obras da instituição.

O critério para a escolha dos casos foi que deveriam ser empreendimentos públicos licitados e executados integralmente no período de 2008 a 2010 possibilitando assim a verificação dos custos previstos e realizados de cada empreendimento.

Após a realização da coleta de dados foi possível realizar uma análise individual e coletiva dos casos. Na análise individual, buscou-se analisar os dados por meio da comparação entre os custos previstos e realizados. O custo total do empreendimento foi comparado com o custo unitário básico de construção (CUB).

$\mathrm{Na}$ análise individual foi possível verificar quais as etapas da obra apresentam as maiores distorções entre o orçamento previsto e o custo real da obra. Foi calculada a variação entre os valores orçados e os pagos.

Caso a falta de padronização ocorreu, foi necessário elaborar outra lógica para realização do processo de orçamentação para obras públicas que permitisse o real controle da obra bem como evitasse as distorções entre o orçamento e o custo real da obra.

\section{Resultados}

Por fazer parte de uma administração federal, a contratação de empresas para a execução de qualquer obra nesta IFES, é realizada através de licitação, com base no menor preço. Para tanto, é necessário fornecer às empresas licitantes cópias do projeto executivo, orçamento convencional e memoriais descritivos.

As obras da administração pública, quando contratadas com terceiros, são necessariamente precedidas de licitação. O objetivo da licitação é garantir a observância do princípio constitucional da isonomia e selecionar a proposta mais vantajosa para a administração. As obras e os serviços somente poderão ser licitados quando houver projeto básico, orçamento detalhado e previsão de recursos orçamentários (Brasil 2002).

Baseado nos dados coletados pode-se perceber que o orçamento elaborado pela equipe de engenheiros da IFES não segue um padrão, ou seja, cada engenheiro elabora de uma forma, o que gera diferença de preços e itens em cada orçamento elaborado por este setor.

Outra atividade que compete a esta equipe de engenheiros é a fiscalização da execução das obras licitadas. A equipe apenas controla e fiscaliza a qualidade e o 
prazo de execução da obra e, também, autoriza os pagamentos mensais para a empresa contratada, não interferindo na forma como os insumos serão adquiridos nem na forma de contratação dos funcionários da empresa executora. Esses pagamentos mensais são feitos baseados no orçamento convencional, verificando quais itens e/ou atividades foram executadas no período. Quando algum item e/ou atividade não estiver totalmente concluído (100\%), como por exemplo, o item estrutura, é estimado um percentual de acordo como bom senso do engenheiro da IFES e da empresa contratada. Salienta-se que este percentual nem sempre corresponde ao executado no período.

Através da observação direta e participante no setor de engenharia da Instituição Federal de Ensino Superior (IFES) estudada, foi possível identificar o processo de planejamento e orçamentação (Figura 2). Este processo funciona da seguinte forma:

- Programa de necessidades: antes de iniciar o empreendimento, é levantada as principais necessidades da Instituição e do setor que solicitou a execução do empreendimento;

- Estudo preliminar ou Anteprojeto: após a definição do empreendimento, a equipe de arquitetos da IFES elabora um estudo preliminar que será aprovado pelo setor solicitante e, então, ser encaminhado para elaboração do projeto executivo;

- Projeto executivo: de posse do anteprojeto, a equipe de arquitetos decide se o projeto executivo será elaborado por eles ou se será elaborado por empresa terceirizada através de licitação;

- Memorial descritivo: após a elaboração do projeto executivo e da listagem dos principais serviços, a equipe de engenheiros da IFES elabora o memorial descritivo que fará parte da licitação da obra;

- Orçamento convencional: após a elaboração do projeto executivo, da listagem e quantificação dos principais serviços, a equipe de engenheiros faz a pesquisa de preços e então elabora o orçamento convencional que fará parte da licitação da obra;

- Licitação: de posse do projeto executivo, memorial descritivo e orçamento convencional, a comissão de licitação da IFES elabora o edital e faz a abertura e julgamento das propostas;

- Contrato: escolhida a empresa vencedora é elaborado o contrato administrativo para realização da obra;

- Fiscalização da obra: após o contrato assinado e emitida a ordem de serviço para início da obra, a equipe de engenheiros inicia a fase de 
fiscalização e controle da obra. Este controle é feito utilizando o orçamento convencional. As medições também são feitas utilizando o orçamento convencional;

- Recebimento da obra: após a conclusão da obra são elaborados os termos de recebimento provisório e recebimento definitivo.

Figura 2. Descrição do processo de planejamento e orçamentão. Curitiba, 2010.

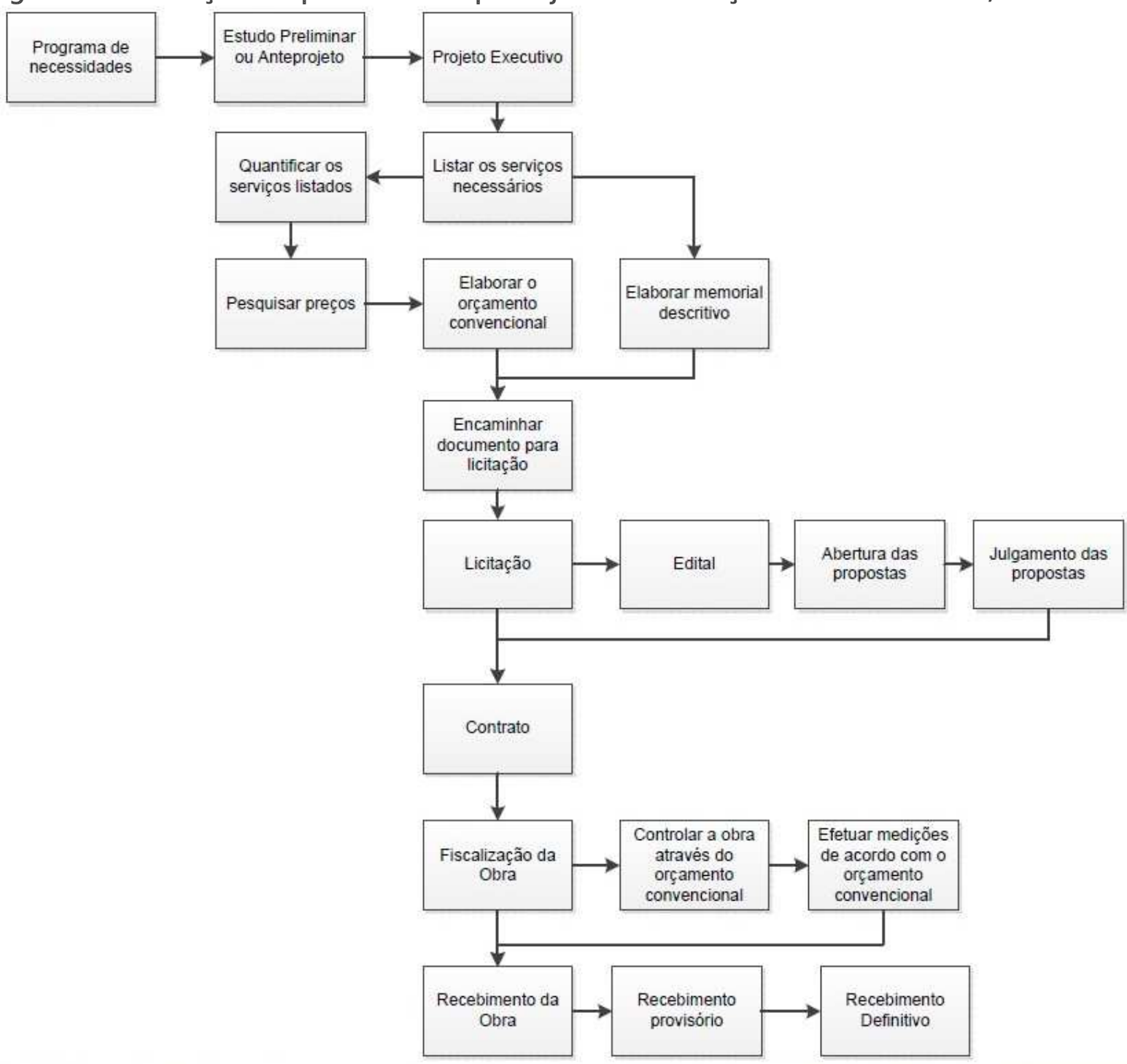

Fonte: Autoria própria (2010).

\section{Obra 1}

A obra 1 é uma edificação térrea com área de aproximadamente $350 \mathrm{~m}^{2}$, que abrigará o centro de convivência para alunos de um dos setores da IFES estudada. Neste centro de convivência estão previstas quatro salas para os 
centros acadêmicos dos cursos bem como dois ambientes reservados para a instalação das empresas-júnior.

A construção desse centro de convivência é uma reivindicação dos alunos e da diretoria do setor, uma vez que devido à criação de novos cursos e aumento do número de vagas, conforme previsto no programa REUNI (Reestruturação e Expansão das Universidades Federais), as salas ocupadas pelos centros acadêmicos e empresas-júnior ocupavam locais estratégicos dentro do bloco didático existente.

O prazo previsto para a execução desta obra foi de 180 dias e a obra foi executada em 350 dias.

A planilha do orçamento convencional foi elaborada em dezembro de 2008 e a construção da edificação foi concluída em março de 2010. A partir das planilhas de orçamentos obtidas (previsto e realizado) foi possível fazer um comparativo entre os valores e as porcentagens prevista e realizada das principais etapas da construção.

Os valores previstos no momento da licitação e os valores reais da obra apresentam diferenças em termos de valores orçados, quantitativos apresentados além de itens que foram executados, mas não estavam previstos no momento da licitação (Quadro 1).

Pode-se perceber que as etapas que obtiveram as maiores distorções nos valores orçados e as maiores variações nos percentuais foram: movimento de terra e drenagem do terreno ( $\mathbb{R} \$-1.124,20 ; 460,71 \%)$, instalações hidráulicas ( $R$ \$ $86.919,59 ;-89,57 \%)$, instalações elétricas ( $R \$-67.435,09 ; 140,53 \%)$, revestimento de parede $(\mathbb{R} \$-17.701,39 ; 91,24 \%)$, revestimento de pisos $(R \$$ $13.922,49 ; 89,69 \%)$, revestimento de teto ( $R \$-7.549,75 ; 16300 \%)$, pintura ( $R \$$ $7.916,12 ; 99,38 \%)$, elementos metálicos ( $R \$ 2.629,11 ;-82,89 \%)$, serviços complementares $(R \$-3.710,09 ; 8000 \%)$ e limpeza final $(R \$-546,10 ; 110 \%)$.

Essas distorções ocorreram principalmente por que no item das instalações hidráulicas estavam previstos itens para reutilização da água da chuva que não foram executados, pois não constava no projeto executivo e memorial descritivo fornecido no momento da licitação. No item das instalações elétricas, o projeto elétrico fornecido no momento da licitação, não estava de acordo com as especificações e normas técnicas, tendo que ser readequado no momento da execução da obra.

Pode-se perceber, também, que existem diferenças entre as etapas de construção, demonstrando-se assim a falta de planejamento e os erros na elaboração do orçamento convencional para a licitação. Observa-se também que existem distorções nos valores por metro quadrado de construção, sendo o previsto na licitação o valor de $\mathrm{R} \$ 1.203,41 / \mathrm{m}^{2}$ e o valor realizado foi de $\mathrm{R} \$$ $1.306,37 / \mathrm{m}^{2}$, ou seja, o valor real está $8,56 \%$ acima do valor previsto na licitação. 
Não há também equivalência de valores quando estes são comparados com o CUB (Custo Unitário Básico), cujo valor foi de $\mathrm{R} \$ 800,54 / \mathrm{m}^{2}$ (SINDUSCON-PR 2011), para o mês de dezembro de 2008.

Para fazer a comparação dos valores previsto na licitação e o realizado com o CUB, foi acrescido ao valor original do CUB o percentual de $30 \%$ referente ao BDI, obtendo-se assim um CUB calculado de $R \$ 1.040,70 / \mathrm{m}^{2}$. Com base nesse novo valor, observa-se que o valor previsto na licitação está $15,63 \%$ acima do valor do CUB calculado, e o valor efetivamente realizado está $25,53 \%$ acima do valor do CUB calculado.

Quadro 1. Porcentagens previstas e realizadas das principais etapas de construção (obra 1). Curitiba, 2010.

\begin{tabular}{|c|c|c|c|}
\hline Etapas & Previsto & Realizado & Variação \\
\hline Instalações preliminares e limpeza & $0,84 \%$ & $0,31 \%$ & $-62,77 \%$ \\
\hline $\begin{array}{l}\text { Movimento de terra e drenagem do } \\
\text { terreno }\end{array}$ & $0,05 \%$ & $0,29 \%$ & $460,71 \%$ \\
\hline Fundação & $4,27 \%$ & $4,61 \%$ & $7,87 \%$ \\
\hline Estrutura & $29,37 \%$ & $29,47 \%$ & $0,35 \%$ \\
\hline Alvenaria & $2,87 \%$ & $4,28 \%$ & $49,09 \%$ \\
\hline Impermeabilizações & $6,44 \%$ & $1,55 \%$ & $-75,92 \%$ \\
\hline Cobertura & $6,63 \%$ & $7,91 \%$ & $19,40 \%$ \\
\hline Instalações hidráulicas & $23,10 \%$ & $2,41 \%$ & $-89,57 \%$ \\
\hline Instalações elétricas & $9,87 \%$ & $23,74 \%$ & $140,53 \%$ \\
\hline Revestimento paredes & $3,88 \%$ & $7,42 \%$ & $91,24 \%$ \\
\hline Revestimento pisos & $3,10 \%$ & $5,88 \%$ & $89,68 \%$ \\
\hline Revestimento teto & $0,01 \%$ & $1,64 \%$ & $16.300,00 \%$ \\
\hline Esquadrias de madeira & $0,73 \%$ & $0,66 \%$ & $-9,59 \%$ \\
\hline Esquadrias metálicas & $4,56 \%$ & $3,48 \%$ & $-23,68 \%$ \\
\hline Pintura & $1,60 \%$ & $3,19 \%$ & $99,38 \%$ \\
\hline Vidros & $0,81 \%$ & $1,30 \%$ & $60,49 \%$ \\
\hline Acessórios, louças e metais sanitários & $0,86 \%$ & $0,61 \%$ & $-29,07 \%$ \\
\hline Elementos metálicos & $0,76 \%$ & $0,13 \%$ & $-82,89 \%$ \\
\hline Instalações mecânicas & $0,00 \%$ & $0,00 \%$ & $0,00 \%$ \\
\hline Serviços complementares & $0,01 \%$ & $0,81 \%$ & $8.000,00 \%$ \\
\hline Paisagismo & $0,15 \%$ & $0,11 \%$ & $-26,67 \%$ \\
\hline Limpeza final & $0,10 \%$ & $0,21 \%$ & $110,00 \%$ \\
\hline Valor total (R\$) & $424.236,78$ & $460.535,96$ & \\
\hline $\mathrm{R} \$ / \mathrm{m}^{2}$ & $1.203,41$ & $1.306,37$ & \\
\hline CUB DEZ/08 $\left(\mathrm{R} \$ / \mathrm{m}^{2}\right)$ & \multicolumn{2}{|c|}{800,54} & \\
\hline
\end{tabular}

Fonte: Autoria própria (2010).

\section{Obra 2}

A obra 2 é uma edificação, com três pavimentos e área de $1.571 \mathrm{~m}^{2}$, que abrigará as novas salas de aula para um dos setores da IFES estudada. Nesta edificação 
foram construídas nove salas de aula além de uma área destinada à ampliação da biblioteca.

A construção desse novo bloco de salas de aula fez-se necessário devido à criação de novos cursos e aumento do número de vagas, conforme previsto no programa REUNI.

O prazo previsto para a execução desta obra foi de 300 dias e a obra foi executada em 360 dias. O orçamento desta obra foi realizado em setembro de 2008 e a construção foi concluída em julho de 2010.

A partir das planilhas de orçamentos e custo real da obra foi possível fazer um comparativo entre o valor previsto e o valor realizado e verificar as distorções entre os custos das principais etapas da construção (Quadro 2).

Analisando o quadro comparativo de porcentagens prevista no momento da licitação e a realizada, de cada etapa principal da construção, pode-se perceber que as etapas que obtiveram as maiores distorções nos valores orçados e as maiores variações nos percentuais foram: movimento de terra ( $R$ \$ -42.182,32; $13,55 \%)$, instalações hidráulicas ( $R$ \$ $-27.858,95 ; 253,33 \%)$, elementos metálicos $(R \$-6.685,55 ; 150 \%)$, serviços complementares ( $R \$-12.706,83 ; 120 \%)$ e paisagismo ( $R \$-8.140,00 ; 5.100 \%)$.

Essas distorções ocorreram principalmente por que foram solicitadas, durante a execução da obra, modificações no projeto original tais como a ampliação da biblioteca e a construção de um telhado verde, ocasionando a diferença nos itens orçados.

Pode-se perceber, também, que não há equivalência de valores entre as etapas de construção, demonstrando-se assim a falta de planejamento e os erros na elaboração do orçamento convencional para a licitação.

Para fazer a comparação dos valores previsto na licitação e o realizado com o CUB, foi acrescido ao valor original o percentual de $30 \%$ referente ao BDI, obtendo-se assim o valor de $\mathrm{R} \$ 1.023,65 / \mathrm{m}^{2}$.

Com base nesse novo dador, observa-se que o valor previsto na licitação está $17,62 \%$ acima do CUB calculado, e o valor efetivamente realizado está $0,51 \%$ abaixo do CUB calculado.

Como o valor real está muito próximo do valor do CUB pode-se concluir que não há critérios para a elaboração do orçamento durante a licitação, pois este está acima dos valores reais e CUB do período estudado. 
Quadro 2. Porcentagens previstas e realizadas das principais etapas de construção (obra 2). Curitiba, 2010.

\begin{tabular}{|c|c|c|c|}
\hline Etapas & Previsto & Realizado & Variação \\
\hline Serviços preliminares & $2,21 \%$ & $3,17 \%$ & $43,44 \%$ \\
\hline Movimento de terra & $0,20 \%$ & $2,91 \%$ & $1.355,00 \%$ \\
\hline Fundação & $4,00 \%$ & $5,81 \%$ & $45,25 \%$ \\
\hline Estrutura & $20,93 \%$ & $30,89 \%$ & $47,59 \%$ \\
\hline Alvenaria & $8,57 \%$ & $4,23 \%$ & $-50,64 \%$ \\
\hline Impermeabilização & $0,61 \%$ & $0,66 \%$ & $8,20 \%$ \\
\hline Cobertura & $3,89 \%$ & $4,57 \%$ & $17,48 \%$ \\
\hline $\begin{array}{l}\text { Instalação hidráulica, sanitária e } \\
\text { incêndio }\end{array}$ & $0,75 \%$ & $2,65 \%$ & $253,33 \%$ \\
\hline Instalação elétrica, telefone e lógica & $6,37 \%$ & $8,86 \%$ & $39,09 \%$ \\
\hline Revestimento de parede & $20,63 \%$ & $11,41 \%$ & $-44,69 \%$ \\
\hline Revestimento de piso & $5,20 \%$ & $5,82 \%$ & $11,92 \%$ \\
\hline Revestimento de teto & $5,02 \%$ & $1,17 \%$ & $-76,69 \%$ \\
\hline Esquadrias de madeira & $0,50 \%$ & $0,49 \%$ & $-2,00 \%$ \\
\hline Esquadrias metálicas & $15,15 \%$ & $9,37 \%$ & $-38,15 \%$ \\
\hline Pintura & $1,54 \%$ & $2,28 \%$ & $48,05 \%$ \\
\hline Vidros & $2,73 \%$ & $2,19 \%$ & $-19,78 \%$ \\
\hline Acessórios, louças e metais sanitários & $0,00 \%$ & $0,00 \%$ & $0,00 \%$ \\
\hline Elementos metálicos & $0,32 \%$ & $0,80 \%$ & $150,00 \%$ \\
\hline Instalações mecânicas & $0,00 \%$ & $0,00 \%$ & $0,00 \%$ \\
\hline Serviços complementares & $0,80 \%$ & $1,76 \%$ & $120,00 \%$ \\
\hline Paisagismo & $0,01 \%$ & $0,52 \%$ & $5.100,00 \%$ \\
\hline Limpeza final & $0,60 \%$ & $0,45 \%$ & $-25,00 \%$ \\
\hline Valor $(\mathrm{R} \$)$ & $1.864 .102,19$ & $1.576 .691,98$ & \\
\hline $\mathrm{R} \$ / \mathrm{m}^{2}$ & $1.204,02$ & $1.018,38$ & \\
\hline CUB SET/08 $\left(\mathrm{R} \$ / \mathrm{m}^{2}\right)$ & \multicolumn{2}{|c|}{787,42} & \\
\hline
\end{tabular}

Fonte: Autoria própria (2010).

\section{Obra 3}

A obra 3 é uma edificação, com dois pavimentos e área de $881,72 \mathrm{~m}^{2}$, que abrigará as novas salas de aula de outro setor da IFES estudada. Nesta edificação foram construídas oito salas de aula. O prazo previsto para a execução desta obra foi de 180 dias e a obra foi executada em 360 dias.

As planilhas de orçamentos da obra foram elaboradas em junho de 2008 e a construção foi concluída em maio de 2010. A partir das planilhas de orçamentos e o custo real da obra, foi possível fazer um comparativo entre o valor previsto e o valor realizado e identificar as distorções de custo em cada uma das etapas da construção (Quadro 3).

O quadro comparativo de porcentagens prevista no momento da licitação e a realizada, de cada etapa principal da construção, permite analisar que as etapas com maiores distorções nos valores orçados e as maiores variações nos percentuais foram: serviços preliminares $(R \$-16.602,54 ; 61,56 \%)$, movimento de 
terra ( $\mathbb{R} \$-32.345,77 ; 31.600 \%)$, impermeabilização ( $\$$ \$ 2.893,44; $-57,78 \%$ ), revestimento de piso ( $\mathrm{R} \$-22.022,23 ; 54,815)$ e limpeza final ( $\mathrm{R} \$ 2.922,11$; $56,52 \%)$.

Essas distorções ocorreram principalmente porque foram solicitadas durante a execução da obra modificações no projeto original tais como locação da obra e a execução de escada de acesso ao segundo pavimento, ocasionando a diferença nos itens orçados.

Para fazer a comparação dos valores previsto na licitação e o realizado com o CUB, foi acrescido ao valor original do CUB o percentual de $30 \%$ referente ao BDI, obtendo-se assim um CUB calculado de $R \$ 1.000,95 / \mathrm{m}^{2}$. Com base nesse novo valor, observa-se que o valor previsto na licitação está $23 \%$ acima do valor do CUB calculado, e o valor efetivamente realizado está $15,55 \%$ acima do valor do CUB calculado.

Quadro 3. Porcentagens previstas e realizadas das principais etapas de construção (obra 3). Curitiba, 2010.

\begin{tabular}{|c|c|c|c|}
\hline Etapas & Previsto & Realizado & Variação \\
\hline Serviços preliminares & $2,94 \%$ & $4,75 \%$ & $61,56 \%$ \\
\hline Movimento de terra & $0,01 \%$ & $3,17 \%$ & $31.600,00 \%$ \\
\hline Fundação & $3,84 \%$ & $3,45 \%$ & $-10,16 \%$ \\
\hline Estrutura & $24,85 \%$ & $29,16 \%$ & $17,34 \%$ \\
\hline Alvenaria & $3,42 \%$ & $3,23 \%$ & $-5,56 \%$ \\
\hline Impermeabilização & $0,45 \%$ & $0,19 \%$ & $-57,78 \%$ \\
\hline Cobertura & $3,16 \%$ & $3,75 \%$ & $18,67 \%$ \\
\hline $\begin{array}{l}\text { Instalação hidráulica, sanitária e } \\
\text { incêndio }\end{array}$ & $2,00 \%$ & $2,25 \%$ & $12,50 \%$ \\
\hline Instalação elétrica, telefone e lógica & $17,54 \%$ & $13,15 \%$ & $-25,03 \%$ \\
\hline Revestimento de paredes & $13,52 \%$ & $11,17 \%$ & $-17,38 \%$ \\
\hline Revestimento de pisos & $4,47 \%$ & $6,92 \%$ & $54,81 \%$ \\
\hline Revestimento de teto & $3,31 \%$ & $2,41 \%$ & $-27,19 \%$ \\
\hline Esquadrias de madeira & $0,83 \%$ & $0,93 \%$ & $12,05 \%$ \\
\hline Esquadrias metálicas & $4,50 \%$ & $3,31 \%$ & $-26,44 \%$ \\
\hline Pintura & $2,75 \%$ & $2,10 \%$ & $-23,64 \%$ \\
\hline Vidros & $1,00 \%$ & $1,07 \%$ & $7,00 \%$ \\
\hline Acessórios, louças e metais sanitários & $5,42 \%$ & $5,08 \%$ & $-6,27 \%$ \\
\hline Elementos metálicos & $0,00 \%$ & $0,00 \%$ & $0,00 \%$ \\
\hline Instalações mecânicas & $5,44 \%$ & $3,69 \%$ & $-32,17 \%$ \\
\hline Serviços complementares & $0,00 \%$ & $0,00 \%$ & $0,00 \%$ \\
\hline Paisagismo & $0,00 \%$ & $0,00 \%$ & $0,00 \%$ \\
\hline Limpeza final & $0,46 \%$ & $0,20 \%$ & $-56,52 \%$ \\
\hline Valor $(\mathrm{R} \$)$ & $1.085 .534,69$ & $1.019 .752,93$ & \\
\hline $\mathrm{R} \$ / \mathrm{m}^{2}$ & $1.231,16$ & $1.156,55$ & \\
\hline CUB JUN/08 $\left(\mathrm{R} \$ / \mathrm{m}^{2}\right)$ & \multicolumn{2}{|c|}{769,96} & \\
\hline
\end{tabular}

Fonte: Autoria própria (2010). 


\section{Análise conjunta dos casos}

Após analisar cada obra individualmente, foi feita uma análise em conjunto para verificar se as obras apresentam algum padrão nos valores das principais etapas de construção.

A análise do quadro comparativo das obras permite perceber que não existem equivalências entre os percentuais de cada etapa da obra nos valores previstos e realizados nas três obras estudadas. As principais distorções ocorreram nas etapas referentes aos serviços preliminares, movimento de terra, cobertura, instalações elétricas e esquadrias metálicas. Com os resultados obtidos, pode-se perceber que não existe um procedimento padrão para a elaboração dos orçamentos convencionais no momento da licitação, corroborando com o que foi identificado durante a coleta de dados na empresa (Quadro 4).

O orçamento não deve ser exato, porém confiável. Ao orçar uma obra, o orçamentista não pretende acertar o valor exato, mas não deve desviar muito do valor que efetivamente irá custar o empreendimento. O orçamento presta-se a dar uma ideia mais ou menos próxima do valor real. Quanto mais apurado e criterioso for o processo de orçamento, menor será a margem de erro (Mattos 2006). Corroborando com a ideia do autor, salienta-se que como as obras estudadas são de mesma natureza, os orçamentos deveriam ter valores por metro quadrado semelhantes. 
Quadro 4. Análise conjunta das porcentagens previstas e realizadas das principais etapas de construção. Curitiba, 2010.

\begin{tabular}{|c|c|c|c|c|c|c|}
\hline Etapas & \multicolumn{2}{|c|}{ Obra 1} & \multicolumn{2}{|c|}{ Obra 2} & \multicolumn{2}{|c|}{ Obra 3} \\
\hline & Previsto & Realizado & Previsto & Realizado & Previsto & Realizado \\
\hline Serviços preliminares & $0,84 \%$ & $0,31 \%$ & $2,21 \%$ & $3,17 \%$ & $2,94 \%$ & $4,75 \%$ \\
\hline Movimento de terra & $0,05 \%$ & $0,29 \%$ & $0,20 \%$ & $2,91 \%$ & $0,00 \%$ & $3,17 \%$ \\
\hline Fundação & $4,27 \%$ & $4,61 \%$ & $4,00 \%$ & $5,81 \%$ & $3,84 \%$ & $3,45 \%$ \\
\hline Estrutura & $29,37 \%$ & $29,47 \%$ & $20,93 \%$ & $30,89 \%$ & $24,85 \%$ & $29,16 \%$ \\
\hline Alvenaria & $2,87 \%$ & $4,28 \%$ & $8,57 \%$ & $4,23 \%$ & $3,42 \%$ & $3,23 \%$ \\
\hline Impermeabilizações & $6,44 \%$ & $1,55 \%$ & $0,61 \%$ & $0,66 \%$ & $0,45 \%$ & $0,19 \%$ \\
\hline Cobertura & $6,63 \%$ & $7,91 \%$ & $3,89 \%$ & $4,57 \%$ & $3,16 \%$ & $3,75 \%$ \\
\hline Instalações hidráulicas & $23,10 \%$ & $2,41 \%$ & $0,75 \%$ & $2,65 \%$ & $2,00 \%$ & $2,25 \%$ \\
\hline Instalações elétricas & $9,87 \%$ & $23,74 \%$ & $6,37 \%$ & $8,86 \%$ & $17,54 \%$ & $13,15 \%$ \\
\hline Revestimento paredes & $3,88 \%$ & $7,42 \%$ & $20,63 \%$ & $11,41 \%$ & $13,52 \%$ & $11,17 \%$ \\
\hline Revestimento pisos & $3,10 \%$ & $5,88 \%$ & $5,20 \%$ & $5,82 \%$ & $4,47 \%$ & $6,92 \%$ \\
\hline Revestimento teto & $0,00 \%$ & $1,64 \%$ & $5,02 \%$ & $1,17 \%$ & $3,31 \%$ & $2,41 \%$ \\
\hline Esquadrias de madeira & $0,73 \%$ & $0,66 \%$ & $0,50 \%$ & $0,49 \%$ & $0,83 \%$ & $0,93 \%$ \\
\hline Esquadrias metálicas & $4,56 \%$ & $3,48 \%$ & $15,15 \%$ & $9,37 \%$ & $4,50 \%$ & $3,31 \%$ \\
\hline Pintura & $1,60 \%$ & $3,19 \%$ & $1,54 \%$ & $2,28 \%$ & $2,75 \%$ & $2,10 \%$ \\
\hline Vidros & $0,81 \%$ & $1,30 \%$ & $2,73 \%$ & $2,19 \%$ & $1,00 \%$ & $1,07 \%$ \\
\hline Acessórios, louças e metais sanitários & $0,86 \%$ & $0,61 \%$ & $0,00 \%$ & $0,00 \%$ & $5,42 \%$ & $5,08 \%$ \\
\hline Elementos metálicos & $0,76 \%$ & $0,13 \%$ & $0,32 \%$ & $0,80 \%$ & $0,00 \%$ & $0,00 \%$ \\
\hline Instalações mecânicas & $0,00 \%$ & $0,00 \%$ & $0,00 \%$ & $0,00 \%$ & $5,44 \%$ & $3,69 \%$ \\
\hline Serviços complementares & $0,00 \%$ & $0,81 \%$ & $0,80 \%$ & $1,76 \%$ & $0,00 \%$ & $0,00 \%$ \\
\hline Paisagismo & $0,15 \%$ & $0,11 \%$ & $0,00 \%$ & $0,52 \%$ & $0,00 \%$ & $0,00 \%$ \\
\hline Limpeza final & $0,10 \%$ & $0,21 \%$ & $0,60 \%$ & $0,45 \%$ & $0,46 \%$ & $0,20 \%$ \\
\hline Valor total (R\$) & $424.236,78$ & $460.535,96$ & $1.864 .102,19$ & $1.576 .691,98$ & $1.085 .534,69$ & $1.019 .752,93$ \\
\hline $\mathrm{R} \$ / \mathrm{m}^{2}$ & $1.203,41$ & $1.306,37$ & $1.204,02$ & $1.018,38$ & $1.231,16$ & $1.156,55$ \\
\hline $\mathrm{CUB}\left(\mathrm{R} \$ / \mathrm{m}^{2}\right)$ & \multicolumn{2}{|c|}{800,54} & \multicolumn{2}{|c|}{787,42} & \multicolumn{2}{|c|}{769,96} \\
\hline
\end{tabular}

Fonte: Autoria própria (2010). 


\section{Orçamento executivo como ferramenta ao processo de planejamento e controle de custos de obras públicas}

Tradicionalmente, os orçamentos de obras de edifícios são estruturados de forma a agrupar os serviços de mesma natureza em uma mesma conta, sem considerar que estes serviços são feitos em momentos e em ambientes diferentes.

A fiscalização da IFES, baseada no orçamento convencional, faz as medições mensais a fim de verificar quais itens e/ou atividades foram executados no período. Quando algum item e/ou atividade não estiver totalmente concluído (100\%), como por exemplo, o item da superestrutura, é estimado um percentual conforme o bom senso da fiscalização da IFES e da empresa contratada, percentual este que nem sempre corresponde ao executado no período.

O orçamento convencional por ser elaborado por unidades de serviço dificulta a previsão de serviços essenciais para a completa execução do empreendimento, como exemplos, citam-se a rampa de acesso e os equipamentos de reaproveitamento de água pluvial, na obra 1, previstos em projetos, mas ausentes no orçamento convencional fornecido na licitação. Com isso, a fiscalização deve decidir se irá fazer um aditivo contratual ou se haverá uma nova licitação para a conclusão da edificação.

Esse aditivo tem restrições e limites legais, por ser uma obra de construção e não de reforma, o valor máximo permitido pela legislação é de $25 \%$ do valor contratado para obras novas e $50 \%$ do valor contratado para obras de reforma.

Outra desvantagem da utilização do orçamento convencional é a dificuldade em que a fiscalização da IFES e empresa contratada têm em determinar os valores e percentuais de serviços que não foram concluídos no período da medição.

Com o orçamento executivo é possível prever com maior eficácia, as atividades necessárias para a completa execução da obra. Neste contexto, a lógica do orçamento executivo pode minimizar as distorções que ocorrem entre o orçamento e o custo real da obra. Porém, um orçamento tão detalhado, indicando todos os insumos que serão utilizados, não colabora com a fiscalização da IFES, pois despende muito tempo para ser executado e contém itens que não serão controlados pela fiscalização da IFES. Não se deve planejar o que não será controlado.

As etapas para realizar um orçamento executivo são (Limmer 1997, Librelotto et al. 1998, Santos et al. 2002, Bazanelli et al. 2003):

- Análise dos projetos executivos, memoriais descritivos e especificações;

- Identificação dos serviços - Programação da obra; 
- Levantamento de quantitativos de materiais por atividades;

- Levantamento da mão-de-obra e equipamentos por atividade;

- Alocação dos recursos às atividades;

- Custo da mão-de-obra, equipamentos e materiais por atividade.

Seguindo estes tópicos foi realizado um estudo sobre a utilização na íntegra do orçamento executivo em obras públicas. Este estudo mostrou que um orçamento tão detalhado não é vantajoso para a empresa estudada, pois contém itens que não serão controlados pela equipe de fiscalização da IFES, como por exemplo, os insumos mão-de-obra e materiais.

Por esta razão, para melhorar o desempenho da fiscalização da IFES, é proposta uma variação no orçamento executivo. A principal diferença entre o orçamento executivo proposto por Limmer (1997), Librelotto et al. (1998), Santos et al. (2002), Bazanelle et al. (2003) e a lógica proposta para orçamento executivo para obras públicas relatada neste artigo é que, no orçamento executivo, todas as composições dos serviços a serem realizados são detalhadas. A lógica proposta trata apenas dos serviços que serão realizados, pois a IFES controla apenas os serviços e não os insumos (Quadro 5).

Quadro5. Exemplo do orçamento executivo proposto.

\begin{tabular}{|c|c|c|c|c|c|}
\hline & & Unidade & Quantidade & $\begin{array}{c}\text { Preço } \\
\text { Unitário }\end{array}$ & $\begin{array}{l}\text { Preço } \\
\text { Total }\end{array}$ \\
\hline 8 & Ambiente 1 & & & & \\
\hline 8.1 & Esquadrias & & & & \\
\hline 8.1.1 & Esquadrias de madeira & & & & \\
\hline 8.1.1.1 & Vergas & $m^{2}$ & & & \\
\hline 8.1.1.2 & Porta completa & $c j$ & & & \\
\hline 8.1.1.3 & Pintura & $m^{2}$ & & & \\
\hline 8.2 & Revestimentos & & & & \\
\hline 8.2 .1 & Revestimento de parede & & & & \\
\hline 8.2.1.1 & Chapisco & $m^{2}$ & & & \\
\hline 8.2 .1 .2 & Emboço & $m^{2}$ & & & \\
\hline 8.2 .1 .3 & Reboco & $m^{2}$ & & & \\
\hline 8.2.1.4 & Pintura & $m^{2}$ & & & \\
\hline 8.2 .2 & Revestimento de piso & & & & \\
\hline 8.2 .2 .1 & Piso cimentado & $m^{2}$ & & & \\
\hline 8.2 .3 & Revestimento de teto & & & & \\
\hline 8.2.3.1 & Chapisco & $m^{2}$ & & & \\
\hline 8.2 .3 .2 & Emboço & $m^{2}$ & & & \\
\hline 8.2 .3 .3 & Reboco & $m^{2}$ & & & \\
\hline 8.2.3.4 & Pintura & $m^{2}$ & & & \\
\hline
\end{tabular}

Fonte: Autoria própria (2012). 
A seguir, apresenta-se um comparativo entre o processo de planejamento e orçamento utilizado na IFES e o processo de planejamento e orçamento proposto (Figura 3). Pode-se observar que a principal diferença entre os dois processos está na fase de orçamentação e controle/fiscalização da obra. Enquanto no processo atual é utilizado o orçamento convencional, no modelo proposto é sugerido a utilização do orçamento executivo separando os quantitativos por pavimentos e/ou ambientes com a finalidade de facilitar o controle da obra. 0 processo de planejamento e orçamento proposto funciona da seguinte forma:

a) Programa de necessidades: antes de iniciar o empreendimento, são levantadas as principais necessidades da Instituição e do setor que solicitou a execução do empreendimento;

b) Estudo preliminar ou anteprojeto: após a definição do empreendimento, a equipe de arquitetos da IFES elabora um estudo preliminar que será aprovado pelo setor solicitante e então ser encaminhado para a elaboração do projeto executivo;

c) Orçamento estimativo: baseado no histórico de custos das obras já concluídas;

d) Projeto executivo: de posse do anteprojeto, a equipe de arquitetos decide se o projeto executivo será elaborado por eles ou se será elaborado por empresa terceirizada através de licitação;

e) Memorial descritivo: após a elaboração do projeto executivo e da programação da obra por pavimentos e/ou ambientes, a equipe de engenheiros da IFES elabora o memorial descritivo que fará parte da licitação da obra;

f) Orçamento executivo: após a elaboração do projeto executivo e da programação da obra por pavimentos e/ou ambientes, a equipe de engenheiros faz o levantamento dos quantitativos dos serviços por pavimentos e/ou ambientes para então, com base na tabela SINAPI, determinar os custos dos serviços por pavimentos e/ou ambientes;

g) Licitação: de posse do projeto executivo, memorial descritivo e orçamento executivo, a comissão de licitação da IFES elabora o edital e faz a abertura e julgamento das propostas;

h) Contrato: escolhida a empresa vencedora é elaborado o contrato administrativo para realização da obra;

i) Fiscalização da obra: após o contrato assinado e emitida a ordem de serviço para início da obra, a equipe de engenheiros inicia a fase de fiscalização e controle da obra. Este controle será feito utilizando o 
orçamento executivo com base na programação da obra por pavimentos e/ou ambientes. As medições também serão feitas utilizando o orçamento executivo;

j) Recebimento da obra: após a conclusão da obra serão elaborados os termos de recebimento provisório e recebimento definitivo.

Outra característica do orçamento executivo proposto para obras públicas é a utilização dos pontos hidráulicos e elétricos baseados na tabela do Sistema Nacional de Pesquisa de Custos e Índices da Construção Civil (SINAPI), facilitando assim a precificação e posterior controle e medição desses pontos.

O SINAPI é um sistema de pesquisa mensal que informa os custos e índices da construção civil e tem a Caixa Econômica Federal e o Instituto Brasileiro de Geografia e Estatística (IBGE) como responsáveis pela divulgação oficial dos resultados, manutenção, atualização e aperfeiçoamento do cadastro de referências técnicas, métodos de cálculo e do controle de qualidade dos dados disponibilizados pelo SINAPI. Este sistema constitui ferramenta útil para elaboração e análise de orçamentos, estimativas de custos, reajustamentos de contratos e planejamentos de investimentos (Caixa Econômica Federal 2010). 
Figura 3. Comparativo entre os processos de planejamento e orçamento utilizado e proposto. PROCESSO DE PLANEIAMENTO E ORÇAMENTO UTILIZADO

PROPOSTA DE PLANEJAMENTO E ORCAMENTO
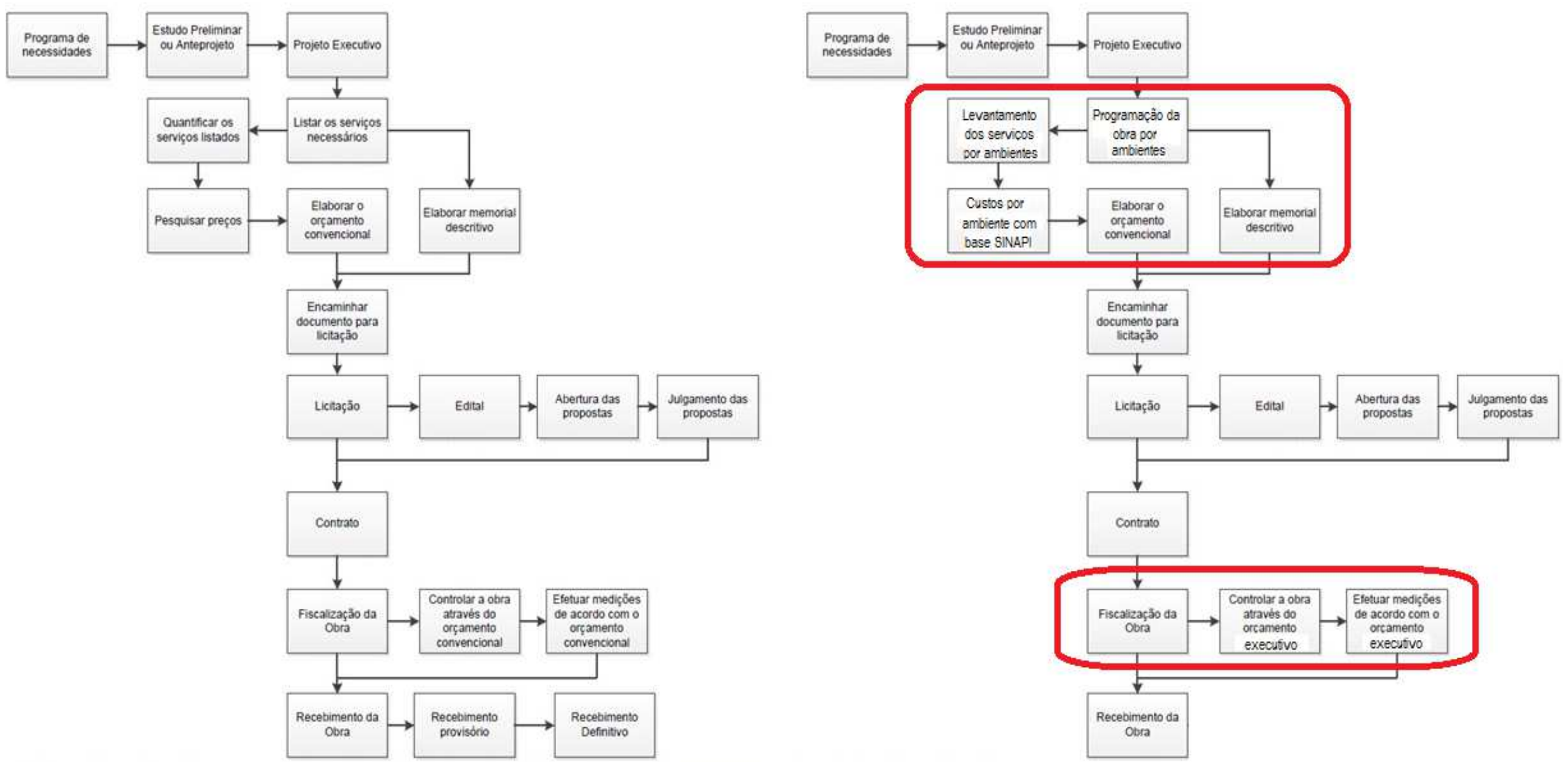

Fonte: Autoria própria (2012) 


\section{Conclusão}

Comparando os dois métodos de orçamento (convencional versus executivo), observam-se várias diferenças entre eles. Enquanto o convencional é abrangente e dividido por unidade de serviços, o orçamento executivo preocupa-se em como a obra será executada.

O orçamento convencional é um método utilizado com frequência na construção e principalmente no departamento de engenharia da IFES analisada, sendo um dos principais motivos de aditivos contratuais em obras licitadas. Os aditivos geralmente ocorrem ou por que serviços necessários para a conclusão da obra não estavam presentes no orçamento convencional ou então os quantitativos dos serviços não correspondem com a realidade da obra.

Dentre os orçamentos, tradicionalmente classificados, a prática do orçamento convencional é consagrada entre as empresas construtoras, motivo pelo qual, o uso de novas técnicas é dificultado.

O orçamento executivo quando aplicado à construção civil apresenta várias vantagens, tais como: melhor previsão dos custos e das atividades necessárias para a execução do empreendimento. Porém, na administração pública, mas especificamente no estudo de caso analisado, o caso das IFES, que apenas fiscalizam empresas contratadas para a execução das obras, o orçamento executivo não apresenta vantagens, pois apresenta itens que não serão controlados pela fiscalização da IFES.

Mas com pequenas adaptações no orçamento executivo, o orçamento proposto apresenta as mesmas vantagens que o orçamento executivo, com atividades que realmente serão controladas, além de necessitar de um tempo menor para ser elaborado.

De acordo com a estratégia adotada para realizar o orçamento executivo para empresa pública foi verificado que a separação por pavimentos e/ou ambientes, facilita na conferência dos quantitativos e também no método de medição, assim, tanto contratada como contratante ficam satisfeitas, pois os pagamentos realizados estarão próximos da realidade, além de auxiliar no controle de prazo e/ou atividades pendentes, mesmo que essas não sejam uma das funções ou características do orçamento executivo.

Somente poderão ser considerados para efeito de medição e pagamento os serviços e obras efetivamente executados pelo contratado e aprovados pela fiscalização, respeitada a rigorosa correspondência com o projeto e as modificações expressa e previamente aprovadas pelo contratante.

O grande desafio da implantação do modelo de orçamento executivo proposto é uma mudança cultural e organizacional no departamento de engenharia da IFES estudada. 
Na indústria da construção de edificações públicas, as tentativas de industrialização de processos e de tecnologias alternativas não se viabilizam. A mudança cria incerteza e faz com que muitos sejam resistentes ao novo. Por se tratar de obras públicas, a sociedade exige de seus representantes (gestores das obras públicas) transparência nos processos de empreendimentos de infraestrutura. Transparência esta não apenas nos processos de contratos e licitações, mas também nos aspectos ambientais e, principalmente, de custos, os quais são ampliados por causa dos processos produtivos adotados, repletos de desperdícios e retrabalhos.

\section{Referências}

Andrade AC, Souza UEL. Diferentes abordagens quanto ao orçamento de obras habitacionais: Aplicação ao caso do assentamento da alvenaria. In: IX Encontro Nacional de Tecnologia do Meio Ambiente Construído. Foz do Iguaçu: ENTAC, 2002.

Andrade VAA. Modelagem dos custos para casas de classe média. 1996. Dissertação (Mestrado) - Universidade Federal de Santa Catarina. Florianópolis, 1996.

Araújo TDP de. Construção de edifícios /: Orçamento, especificações, cronograma - Notas de aulas. Fortaleza: Universidade Federal do Ceará, 2003.

Ashuri B, Lu J. Time series analysis of ENR construction cost index. Journal of Construction Engineering and Management 2010, 136(11):1227-1237.

Bazanelli ACDR. Uma nova abordagem do orçamento na construção civil frente à filosofia gerencial do pensamento enxuto. Dissertação (Mestrado) Universidade Estadual de Campinas. Campinas, 2003.

Brasil. Tribunal de Contas da União. Obras públicas: Recomendações básicas para a contratação e fiscalização de obras públicas. Brasília: TCU / SECOB, 2002.

Caixa Econômica Federal. SINAPI - Indices da construção civil. Brasília, 2010. Disponível na internet em: http://www1.caixa.gov.br/gov/gov_social/municipal/programa_des_urbano/SIN APl/index.asp [ Acesso em dez. 2010].

Cardoso RS. Orçamento de obras em foco: Um novo olhar sobre a engenharia de custos. São Paulo: Pini, 2009.

Castro JEE, Roque RF, Rosa GS, Bonfin NS. Custos administrativos na construção civil - Estudo de caso. In: XVII Encontro Nacional de Engenharia de Produção. Gramado, 1997. 
Coêlho RS de A. Planejamento e controle de custos nas edificações. São Luís: UEMA, 2006.

Cristóbal JRS. Time, cost and quality in a road building project. Journal of Construction Engineering and Management 2009, 135(11):1271-1274.

Dias PRV. Engenharia de custos: Uma metodologia de orçamentação para obras civis. Itaperuna: Hoffmann, 2006.

Domingues MA. Orçamentação de empreendimentos de arquitetura e engenharia civil: Uma solução metodológica para atender a Lei de Responsabilidade Fiscal e a Lei de Licitações. São Paulo: UNIP, 2003.

Freires AP, Pamplona EO. Um enfoque no BDI de empresas construtoras de pequeno porte com a utilização das ferramentas de custeio $\mathrm{ABC} / \mathrm{ABM}$. In: IX Congresso Internacional de Custos. Florianópolis, 2005.

Galvão MA de S, Heineck LF, Kliemann Neto FJ. Orçamentos operacionais e sua aplicação na gerência de construção civil. In: 10․ Encontro Nacional de Engenharia de Produção. Belo Horizonte, 1990.

Gil AC. Métodos e técnicas de pesquisa social. São Paulo: Atlas, 2007.

Goldman P. Sistema de planejamento e controle de custos na construção civil: Subsetor edificações. Dissertação (Mestrado) - Universidade Federal Fluminense. Niterói, 1999.

González MAS. Noções de orçamento e planejamento de obras. São Leopoldo: UNISINOS, 2008.

International Project Management Association (IPMA). IPMA Competence Baseline Version 3.0. IPMA, 2006.

Knolseisen PC. Compatibilização de orçamento com o planejamento do processo de trabalho para obras de edificações. Dissertação (Mestrado) - Universidade Federal de Santa Catarina. Florianópolis, 2003.

Librelotto LI, Ferroli PCM, Rados GV. Custos na construção civil: Uma análise teórica e comparativa. In: VII Encontro Nacional de Tecnologia do Ambiente Construído. Florianópolis: ANTAC, 1998.

Limmer CV. Planejamento, orçamentação e controle de projetos e obras. Rio de Janeiro: LTC, 1997.

Mattos AD. Como preparar orçamentos de obras: Dicas para orçamentistas. São Paulo: Editora Pini, 2006. 
Mattos RMM, Cruz ALG. Metodologia para formação de preços de obras empreitadas no setor da construção civil. Encontro técnico: Economicidade. Salvador: TCM/BA, 2007.

Nunes WCG, Freire AE. Auditoria de projetos: A análise econômica das obras públicas. In: VII Simpósio Nacional de Auditoria de Obras Públicas. Brasília, Distrito Federal, 2002.

Oliveira LM, Perez JRJH. Contabilidade de custos para não contadores. São Paulo: Atlas, 2000.

Perreira Filho Jl, Rocha RA, Silva LM. Planejamento e controle da produção na construção civil para gerenciamento de custos. In: XXIV Encontro Nacional de Engenharia de Produção. Florianópolis, 2004.

Santos APL, Giadon A, Turra FA, Santos A dos. Crítica ao processo de contratação de obras públicas no Brasil. In: IX Encontro Nacional de Tecnologia do Meio Ambiente Construído. Foz do Iguaçu: ENTAC, 2002.

Santos APL, Turra F, Panzeter A. Viabilidade da aplicação de planejamento e orçamento operacional. In: IX Encontro Nacional de Tecnologia do Meio Ambiente Construído. Foz do Iguaçu: ENTAC, 2002.

Sindicato da Indústria da Construção Civil no Estado do Paraná (SINDUSCON-PR). Tabelas CUB-PR. Curitiba, 2011. Disponível na internet em: http://www.sinduscon-pr.com.br/principal/home/ [ Acesso em jan. 2011].

Souza A, Clemente A. Gestão de custos. São Paulo: Atlas, 2007.

Stoy C, Schalcher H. Residential building projects: Building cost indicators and drivers. Journal of Construction Engineering and Management 2007, $133(2): 139-145$.

Tisaka M. Lei de licitações. Construção Mercado 2005, 43(2).

Tisaka M. Orçamento na construção civil: Consultoria, projeto e execução. São Paulo: Editora Pini, 2006.

Valeriano DL. Moderno gerenciamento de projetos. São Paulo: Pearson Prentice Hall, 2007.

Zdanowicz JE. Orçamento operacional: Uma abordagem prática. Porto Alegre: Sagra, 1984. 